\title{
Perspectives From COPD Subjects on Portable Long-Term Oxygen Therapy Devices
}

\author{
Hejab J AlMutairi MSc RRT RRT-ACCS RRT-NPS, Constance C Mussa PhD RRT RRT-NPS, \\ Clement TM Lambert PhD, David L Vines MHS RRT FAARC, and \\ Shawna L Strickland PhD RRT RRT-NPS RRT-ACCS AE-C FAARC
}

\begin{abstract}
BACKGROUND: Oxygen therapy for patients with COPD and severe hypoxemia requires the use of oxygen delivery devices that allow mobility as needed. However, the characteristics of some devices may limit the freedom of individuals to be as physically active as they desire. Limited mobility may negatively affect the perceived quality of life of individuals with COPD. The aim of this study was to understand perceived limitations that patients with COPD experience in using long-term oxygen therapy (LTOT) devices. METHODS: We performed a qualitative analysis of 311 responses to an open-ended question from a previously deployed electronic survey designed to investigate how LTOT devices affect oxygen-dependent patients with COPD. Our thematic analysis was facilitated by NVivo, a qualitative data analysis software package. This involved identifying patterns and themes within the robust, text-rich data from the open-ended survey question regarding the survey subjects' experiences with their LTOT devices. Cluster analysis was also performed to highlight relationships between various concepts. RESULTS: Themes generated revealed that subjects experienced decreased mobility, which resulted in feelings of decreased autonomy and isolation. We also found that subjects perceived a decrease in quality of life due to their described experience of portable oxygen cylinders being heavy and cumbersome. Subjects described feelings of fear and anxiety due to insufficient support for breathing provided by pulse-dose portable oxygen concentrators, as well as portable oxygen cylinders that run out before they are able to complete errands and other activities of daily living. Some subjects also reported that they willingly pay for liquid oxygen systems out-of-pocket because of the mobility it affords, which in their perception improves their quality of life. CONCULSIONS: Oxygen-dependent individuals with COPD may be at risk of adverse outcomes associated with decreased mobility encouraged by unsatisfactory physical and technical characteristics of portable oxygen cylinders and concentrators. Key words: COPD; long-term; oxygen therapy; mobility; physical activity; quality of life; qualitative; thematic analysis. [Respir Care 2018;63(11):1321-1330. @ 2018 Daedalus Enterprises]
\end{abstract}

\section{Introduction}

Long-term oxygen therapy (LTOT) has demonstrated enhanced survival benefits for individuals with COPD and severe resting hypoxemia. ${ }^{1}$ In the United States, for individuals with COPD to qualify for Medicare coverage of home oxygen, their $\mathrm{S}_{\mathrm{pO}_{2}}$ must be at or below $88 \%$ or their $\mathrm{P}_{\mathrm{aO}}$ must be at or below $55 \mathrm{~mm} \mathrm{Hg}$ at rest while awake

\footnotetext{
Drs Mussa as well as Mr AlMutairi and Mr Vines, are affiliated with the Division of Respiratory Care, Department of Cardiopulmonary Sciences, Rush University Medical Center, College of Health Sciences, Chicago, Illinois. Dr. Strickland is affiliated with Department of Member Services, American Association for Respiratory Care. Dr Lambert is affiliated with the School of Education, University of the West Indies, Mona, Kingston, Jamaica. Mr AlMutairi is also affiliated with King Faisal Specialist Hospital and Research Center, Riyadh, Saudi Arabia.
}

\footnotetext{
Mr AlMutairi presented a version of this paper as an Editors' Choice abstract at the OPEN ForUM of the 2017 AARC Congress, held October 4-7, 2017, in Indianapolis, Indiana.

Mr Vines has disclosed relationships with Aerogen, Bayer Healthcare, Boehringer Ingelheim, CareFusion, Covidien-Medtronic, Halyard, Salter Labs, and Teleflex. The other authors have disclosed no conflicts of interest.
} 
and breathing room air. Individuals diagnosed with COPD who are not hypoxemic at rest based on the above specified criteria qualify for Medicare coverage of home oxygen if (1) they are hypoxemic during exercise testing, and

\section{See the Related Editorial on Page 1452}

(2) there is documented improvement of hypoxemia during exercise with supplemental oxygen. Moreover, for these individuals to continue to have their home oxygen paid for by Medicare, a qualified health care provider must submit documentation annually attesting that oxygen is medically necessary (https://www.cms.gov/medicare-coveragedatabase, Accessed February 12, 2018).

Although supplemental oxygen is an established therapy for individuals with COPD and severe resting hypoxemia, the effect of LTOT devices on patient-centered outcomes such as mobility and quality of life has received very little attention from researchers and clinicians in the United States. Moreover, because LTOT prescriptions do not usually specify the LTOT device, oversight of this aspect of LTOT is often left to third-party payers and durable medical equipment vendors. This situation is unlikely to change in the near future because of the limited and inconclusive evidence regarding the effect of LTOT devices on physical activity and quality of life..$^{2,3}$

Clinicians treating patients with COPD will often discuss with patients the possibility of side effects from the medications being used, including supplemental oxygen. However, these clinicians may not tell their patients how limiting the use of oxygen can be. In many cases, a patient who requires long-term oxygen therapy (LTOT) will be, in effect, tethered to an oxygen delivery device that limits mobility. Because there is currently no cure for COPD, optimizing the quality of life of individuals afflicted with this disease is the primary goal of therapeutic interventions. Physical activity affects an individual's quality of life, and it is therefore important that individuals with COPD who are oxygen dependent have access to oxygen delivery devices that do not compromise their ability to engage in activities of daily living. ${ }^{4-7}$ COPD is a chronic disease that has a strong influence on an individual's psychosocial well-being as well as his or her ability to perform basic life functions such as walking and self-care. Consequently, many studies have tried to identify the factors that could limit a person's ability to cope effectively

Correspondence: Constance C Mussa PhD RRT RRT-NPS, Department of Cardiopulmonary Sciences, Rush University, AAC 765A, 600 S. Paulina St, Chicago, IL 60612. Email: constance_mussa@rush.edu

DOI: $10.4187 /$ respcare. 05916

\section{QUICK LOOK}

\section{Current knowledge}

COPD disease burden may limit the ability to perform activities of daily living. Moreover, long-term oxygen therapy (LTOT) devices designed to support ambulation may prevent them from engaging in physical activity if these devices are too heavy or cumbersome. Decreased mobility due to disease burden or portable LTOT device may negatively affect quality of life. There is a paucity of studies that address the relationship between portable LTOT device and quality of life of oxygen-dependent individuals.

\section{What this paper contributes to our knowledge}

We used qualitative methodology that involved thematic analysis to identify patterns and themes within an open-ended survey. Themes generated revealed that subjects experienced decreased mobility associated with specific perceived LTOT device limitations, resulting in feelings of decreased autonomy, isolation, and perceived decrease in quality of life. Subjects described unsatisfactory physical and technical characteristics of portable oxygen cylinders and concentrators that may place oxygen-dependent individuals with COPD and severe hypoxemia at risk for adverse outcomes associated with decreased mobility.

with this chronic disease, which often compromises their quality of life. ${ }^{8-13}$

A study by Hartman et $\mathrm{al}^{8}$ conducted in the Netherlands to determine the factors associated with physical limitations of COPD patients showed that patients with severe COPD who require LTOT had a lower level of physical activity and thus exhibited a lower quality of life. In addition, a lower level of social interaction and exercise capacity were seen among patients with severe COPD who required LTOT. Although this study identified LTOT use as being independently associated with a significantly lower level of physical activity in individuals with severe COPD, the effect of specific LTOT devices on physical activity was not examined.

Another study showed a significant relationship between quality of life and walking distance, specifically demonstrating that oxygen-dependent patients with COPD who were able to walk only short distances had a lower quality of life than those who were able to walk longer distances. ${ }^{9}$ The results of the study suggested that limited mobility and perceived poor quality of life may lead to high levels of depression and anxiety. However, evidence for the possible effects of LTOT devices on mobility was not mentioned in the study. Conversely, a study by Ar- 


\section{Perspectives From COPD Subjects on LTOT}

nold et $\mathrm{al}^{10}$ did mention the possible effect of such devices on mobility.

Most of the studies that show possible effects of LTOT on quality of life have been performed in Europe. For example, a study conducted in Greece ${ }^{11}$ found that subjects with COPD who used LTOT scored significantly lower $(P<.001)$ in the physical function, social function, and emotional well-being domains compared to the average Greek citizen. Additionally, subjects with COPD who used LTOT scored significantly lower $(P=.05)$ in physical activity than a control group of stable subjects with COPD without hypoxemia. The researchers noted that subjects with COPD in the LTOT group were older, had more severe COPD, and reported worse dyspnea than the control group, which could explain their lower physical activity scores. The results of the study showed no significant association between oxygen-dependent subjects' activities of daily living scores and the type of LTOT device used (liquid oxygen system [LOX] vs portable oxygen concentrators [POC]).

To understand why patients with COPD were not fully compliant with their use of POCs, Arnold et al ${ }^{10}$ conducted a study to determine if factors such as the weight of the LTOT device, operating time, cost, or social stigma of carrying the device in public contribute to this problem. They found that the need for assistance in carrying or walking with a heavy cylinder and social embarrassment could be reasons why these individuals did not adhere to LTOT use.

Based on observations from previous studies on LTOT, it is entirely possible that long-term oxygen use could interfere with one's physical activity and thus negatively impact one's quality of life.

The purpose of this study was to identify potential linkages between LTOT devices and their effects on the subject's physical activity and perceived quality of life. A grounded-theory approach was applied to analyze comments made by patients with COPD in an open-ended survey question to further understand the limitations that patients with COPD in the United States might encounter when using LTOT devices.

\section{Methods}

\section{Subjects and Sample Size}

The study sample is from of a previous study conducted by Mussa et $\mathrm{al}^{12}$ in which an electronic survey designed to measure the perceived satisfaction with LTOT device, mobility, and quality of life of oxygen-dependent individuals was created and posted to the COPD Foundation's social media site (COPD360social). This survey recruited 529 subjects. The COPD360social site is an online social community that allows people with COPD, family members, and caregivers to interact with each other. Of the 529 subjects, 320 completed the open-ended question at the end of the survey that invited subjects to enter qualitative responses related to their experiences with and perspectives on oxygen delivery devices. The question asked: "Do you have any comments or opinions to share about your current oxygen delivery device?"

\section{Study Design}

The qualitative design of this inquiry is based on the interpretation of direct quotations from subjects. This provided another dimension to the broader research frame because experts in qualitative research, such as Patton, ${ }^{13}$ highlight the merits of this approach in terms of "revealing subjects' depth of emotion, the way they have organized their world, their thoughts about what is happening, their experiences and their basic perceptions" (p. 24). Through this design, the researchers provided a framework within which the subjects could respond in ways that reflect their viewpoints about their worlds. Thematic analysis was performed to identify patterns and themes within the large amount of text-rich data received from the open-ended question. This method is a nonlinear analysis process that involves inductive and deductive description and interpretation, integration of manifest and latent content, and drawing thematic maps. Employing this approach to data analysis provided responses to questions such as: What are the concerns of oxygen-dependent individuals with COPD with regard to mobility and quality of life? What reasons do these individuals have for using or not using specific LTOT devices?

\section{Data Analysis}

The NVivo qualitative data analysis software (QSR International Pty Ltd. version 10, 2014) was chosen because of its compatibility with a range of qualitative research designs. ${ }^{14}$ This software facilitated thematic analysis by first allowing the researchers to create an open node structure. The structure involved using general words that are related to specific variables, such as walk, work, fear, breathe, heavy, and anxiety (to name a few), then using axial coding to connect each main category to subcategories. Nodes were created repeatedly in this manner for various constructs to enable the researchers to search for recurring themes in subjects' comments relevant to their perception of the effect of the various portable oxygen delivery devices on their ability to engage in life functions.

The primary goal was to identify potential linkages between LTOT devices and their perceived effect on the physical activity and quality of life of subjects with COPD. After extensive node creation, the software facilitated extraction of distinctive thematic patterns from the data. In addition to the engagement of the software, the data and 
Table 1. Characteristics of Subjects Whose Responses Were Included in the Thematic Analysis, Grouped by Oxygen Therapy Device

\begin{tabular}{|c|c|c|c|c|c|}
\hline Characteristic & $\begin{array}{c}\text { Total } \\
(N=311)\end{array}$ & $\begin{array}{c}\text { LOX } \\
(n=45)\end{array}$ & $\begin{array}{c}\text { POC } \\
(n=80)\end{array}$ & $\begin{array}{c}\text { POCyl } \\
(n=186)\end{array}$ & $\begin{array}{l}P \text { for Group Differences } \\
\text { (LOX vs POC vs POCyl) }\end{array}$ \\
\hline Age, y & $65.6(8.2)$ & $68.07(6.81) \div$ & $66.56(7.67)$ & $64.50(8.51)^{*}$ & .01 \\
\hline \multicolumn{6}{|l|}{ Gender, $n(\%)$} \\
\hline Female & $250(80)$ & $31(69)$ & $67(84)$ & $152(82)$ & \multirow[t]{2}{*}{.09} \\
\hline Male & $61(20)$ & $14(31)$ & $13(16)$ & $34(18)$ & \\
\hline \multicolumn{6}{|l|}{ COPD severity, $n(\%)$} \\
\hline Mild/Moderate & $64(20)$ & $7(16)$ & $22(28)$ & $35(19)$ & \multirow[t]{2}{*}{.17} \\
\hline Severe & $247(80)$ & $38(84)$ & $58(72)$ & $151(81)$ & \\
\hline \multicolumn{6}{|l|}{ Years with COPD } \\
\hline $1-3$ & $35(11)$ & $0(0) \dagger$ & $14(18)^{*}$ & $21(11)^{*}$ & \multirow[t]{3}{*}{.002} \\
\hline $4-6$ & $67(22)$ & $4(9) \ddagger$ & $17(21)$ & $46(25)^{*}$ & \\
\hline$>7$ & $209(67)$ & $41(91) \dagger+$ & $49(61)^{*}$ & $119(64)^{*}$ & \\
\hline \multicolumn{6}{|l|}{ Medicare use, $n(\%)$} \\
\hline No & $80(26)$ & $5(11) \dagger \dagger$ & $28(35)^{*}$ & $47(25)^{*}$ & \multirow[t]{2}{*}{.01} \\
\hline Yes & $231(74)$ & $40(89) \dagger \dagger$ & $52(65)^{*}$ & $139(75)^{*}$ & \\
\hline \multicolumn{6}{|c|}{ Resting oxygen flow, L/min } \\
\hline $1-3$ & $227(73)$ & $24(53) \dagger \dagger$ & $65(81)^{*}$ & $138(74)^{*}$ & \multirow[t]{2}{*}{.003} \\
\hline$\geq 4$ & $84(27)$ & $21(47) \dagger \dagger$ & $15(19)^{*}$ & $48(26)^{*}$ & \\
\hline \multicolumn{6}{|c|}{ Exertional oxygen flow, L/min } \\
\hline $1-3$ & $156(51)$ & $14(34) \dagger$ & $51(62)^{*} \ddagger$ & $91(49) \dagger$ & \multirow[t]{2}{*}{.001} \\
\hline$\geq 4$ & $153(49)$ & $27(66) \dagger$ & $31(38)^{*}+$ & $95(51) \dagger$ & \\
\hline \multicolumn{6}{|l|}{ Daily oxygen use, $\mathrm{h}$} \\
\hline $1-12$ & $54(17)$ & $2(67) \dagger$ & $26(33)^{*}+$ & $26(14) \dagger$ & \multirow[t]{3}{*}{$<.001$} \\
\hline $13-18$ & $24(8)$ & $1(33)$ & $7(67)$ & $16(86)$ & \\
\hline $19-24$ & $233(75)$ & $42(18) \dagger \dagger$ & $47(20)^{*}+$ & $144(62)^{*} \dagger$ & \\
\hline \multicolumn{6}{|c|}{$\begin{array}{l}\text { Data are shown as mean (SD) unless noted as frequency }(\%) \text {. } \\
\text { * Significant difference compared to the LOX group. } \\
\dagger \text { Significant difference compared to POC group. } \\
\text { ¥ Significant difference compared to POCyl group. } \\
\text { LOX = liquid oxygen device } \\
\text { POC = portable oxygen concentrator } \\
\text { POCyl = portable oxygen cylinder }\end{array}$} \\
\hline
\end{tabular}

emerging themes were audited by members of the research team who were experienced in qualitative data analysis.

\section{Results}

Of the 320 responses to the open-ended survey question, 311 were included in the thematic analysis as 3 subjects', comments consisted only of the word "none," and 6 subjects did not provide enough information for us to conclusively ascertain the portable LTOT device they use. The study sample consisted of 250 women (80\%) and 61 men $(20 \%) ; 247(80 \%)$ of the subjects reported that they have severe COPD, 233 (75\%) reported that they use oxygen 19-24 h/d, and 231 (74\%) were Medicare recipients. A recent study using the same sample found that the subjects who used LOX devices were older Medicare users compared with subjects who used POCs and portable oxygen cylinders. ${ }^{12}$ However, the distributions across device groups were not statistically different for gender and COPD severity. Similarly, the group of subjects who were included in this study's thematic analysis who used LOX were older Medicare users (mean age of 68 y compared to mean age of $66 \mathrm{y}$ for all study subjects). Additionally, a higher proportion of the LOX group reported that they had COPD for $>7 \mathrm{y}$ as compared to the proportion of subjects in the POC and portable cylinder groups.

Regarding oxygen use during activity, a higher proportion of subjects in the POC and portable cylinder groups reported using a flow of 1-3 L/min, whereas a higher proportion of subjects in the LOX group reported a flow of $\geq 4 \mathrm{~L} / \mathrm{min}$. A significantly higher proportion of subjects in the portable cylinder group reported a daily oxygen use of 19-24 h. Table 1 presents a summary of the demographic characteristics of the 311 survey subjects who were included in the qualitative analysis. A significantly greater proportion of subjects who identified themselves as Medicare recipients also reported that they use oxygen for 19$24 \mathrm{~h}$, while a significantly greater proportion of those who do not use Medicare reported that they use oxygen for $\leq 18 \mathrm{~h}$. There was no significant difference between Medi- 


\section{Perspectives From COPD Subjects on LTOT}

Table 2. Characteristics of Subjects Whose Responses Were Included in the Thematic Analysis, Grouped by Medicare Status

\begin{tabular}{|c|c|c|c|}
\hline Characteristic & $\begin{array}{l}\text { Medicare } \\
(n=231)\end{array}$ & $\begin{array}{c}\text { No } \\
\text { Medicare } \\
(n=80)\end{array}$ & $\begin{array}{c}P \text { for } \\
\text { Group } \\
\text { Differences }\end{array}$ \\
\hline \multicolumn{4}{|l|}{ Gender, $n(\%)$} \\
\hline Female & $184(80)$ & $66(82)$ & .62 \\
\hline Male & $46(20)$ & $14(18)$ & \\
\hline Missing & 1 & 0 & \\
\hline \multicolumn{4}{|c|}{ COPD severity, $n(\%)$} \\
\hline Mild/moderate & $46(20)$ & $17(21)$ & .81 \\
\hline Severe & $184(80)$ & $63(79)$ & \\
\hline Missing & 1 & 0 & \\
\hline \multicolumn{4}{|l|}{ Years with COPD } \\
\hline $1-3$ & $18(8) \dagger$ & $17(21)^{*}$ & .004 \\
\hline $4-6$ & $53(23)$ & $14(18)$ & \\
\hline$>7$ & $160(69)$ & $49(61)$ & \\
\hline \multicolumn{4}{|l|}{ Daily oxygen use, h } \\
\hline $1-12$ & $34(15) \dagger$ & $20(25)^{*}$ & .001 \\
\hline $13-18$ & $12(5) \dagger$ & $12(15)^{*}$ & \\
\hline $19-24$ & $185(80) \dagger$ & $48(60)^{*}$ & \\
\hline \multicolumn{4}{|c|}{$\begin{array}{l}\text { Exertional oxygen flow, } \\
\mathrm{L} / \mathrm{min}\end{array}$} \\
\hline $1-3$ & $109(48)$ & $47(59)$ & .09 \\
\hline$\geq 4$ & $120(52)$ & $33(41)$ & \\
\hline Missing & 2 & 0 & \\
\hline
\end{tabular}

care recipients and those who do not receive Medicare with regard to gender, COPD severity, and the oxygen flow used during exertion. Table 2 summarizes the demographic characteristics of Medicare recipients compared to those who do not receive Medicare. The sentiments expressed by Medicare recipients were similar to those expressed by subjects who do not receive Medicare.

Based on the systematic analysis of the subjects' comments facilitated by the NVivo software, key concepts relevant to the usage of specific LTOT devices were generated (Table 3). Cluster analysis was also performed to highlight relationships between various concepts. Themes generated revealed that subjects' dominant concerns were mobility, autonomy, isolation, and change in quality of life associated with the type of portable LTOT device to which they had access. Subjects also described their fear and anxiety due to insufficient support for breathing provided by their portable LTOT devices. These dominant and emerging themes are important in providing insights on the perspectives and stated experiences of the subjects.

\section{Mobility}

A dominant concern of subjects was the level of mobility that the LTOT device provided them. Subjects ex- pressed a preference for the portable concentrator over tanks. One subject noted that the "portable concentrator would enable me to go places." Another stated, "In the past, I was using a POC and then had to convert to ' $\mathrm{D}$ ' tanks using a 'home fill' system to fill extra tanks for all trips away from home. I always encouraged COPD patients to stay active. Now, I find that I am the one who has slowed down almost to a stop...."

The frustration with the use of tanks and stated preferences for more movement-friendly devices/equipment was recurrent in the qualitative data. The preference for a more lightweight portable LTOT device, namely, the LOX or $\mathrm{POC}$, is noteworthy because subjects provided practical examples that justified their preference for one device over another. The following comment vivifies one subject's experiences and rationale for preferring a POC over tanks: "With arthritis in hips, knees, and shoulders, I can carry or lift only a limited weight, less than the usual woman's purse. Without my POC, I would be unable to travel."

The emphasis on the type of device and its influence on the subject's mobility was expressed in many ways. The following excerpt from one subject's comments provides another striking description of the power of mobility to alter the subject's entire lifestyle and self- perception: "I felt like an old woman that was about to die when using cylinders with a rolling cart. Hard to pick up and put in car and hard to get back out. I like to go to the beach and visit family out of town. It is too hard to put so many cylinders in car."

This was corroborated by another subject, who stated, "The tank and shoulder bag I carry weigh 5 pounds. For some people that is not a lot, but I am a small woman who has lost a lot of strength over my years with COPD. It is bulky and hard to manage while cleaning the house, working in the yard, taking care of a pet or children, etc. I was disappointed that there was no choice of what type of device I could get. When my pulmonologist prescribed oxygen, the durable medical equipment company simply arrived with the concentrator and tanks. And that was that. This combination is a problem for travel, even for travel by car with an overnight stay. The concentrator is too large and heavy for me to take along, but the tanks don't last long enough to get me through the night."

The data related to mobility indicated that there were concerns of limiting mobility through the use of tanks. Subjects provided clear examples of why mobility is a priority and why LOX or POC is preferred over the use of tanks to engage in their everyday activities.

\section{Autonomy}

The freedom to carry out personal activities with little or no external influence was highlighted as an important dimension of subjects' experiences. Generally, subjects found the use of heavier tanks restrictive, while access to 


\section{Perspectives From COPD SubJects on LTOT}

Table 3. Thematic Analysis Sample

Initial Code

Ease of use

Mobility

Lack of mobility

Lack of mobility/ quality of life

\section{Aesthetics \\ Insufficient support for breathing \\ Insufficient support for breathing \\ Safety \\ Lack of mobility \\ Compact/convenient \\ Cumbersome/heavy \\ Cumbersome/heavy}

live in a climate that has extreme temperature fluctuations and it's hard to go anywhere with oxygen cylinders in my vehicle in the summer heat.

I need a portable (battery powered) concentrator and/or liquid oxygen, paid for by Medicare, to increase my mobility.

I use a portable concentrator for anything outside my home. I don't have the strength to carry tanks.

Tanks are too heavy to use as a back pack usage. A tank needs a better back pack or a cushion for the back pack as it can't be used as a carry along without causing more $\mathrm{O}_{2}$ depletion getting to the destination.

I felt like an old woman that was about to die when using cylinders with a rolling cart. Hard to pick up and put in car and hard to get back out. I like to go to the beach and visit family out of town. It is too hard to put so many cylinders in car.

Using the cylinders restricts time I spend outside my immediate home/yard. While with a cylinder, I'm ready to be *done* . . . so much energy is wasted!

Tanks too heavy, have to put them in my walker to transport them; too heavy for me to carry, can't breathe with their weight on me.

They cut me down to 5 cylinders per month. I was getting 5-10 per week. I tried to go do some of kind of exercise every day, dr. appts, church, and gym. Now I can only go once a week. So I choose church on Sunday. My doctor is trying to get me more bottles so I can go 3 days to rehab.

My portable $\mathrm{O}_{2}$ tanks are very heavy and they don't give enough oxygen while moving around; I need 3 continuous and they only go to 2. I have to use my wheel chair when I go out, because tanks do not give enough oxygen for me to walk.

Continuous mode would be better when active and walking, pulse is not good, cannot move a lot.

My portable oxygen allows me to live my life to the best of my abilities; without it I would be completely dependent on outside help.

I am so blessed to own my own concentrator and have service. I have difficulty lugging the big tanks as evidenced by a reduction in blood $\mathrm{O}_{2}$ by oximeter and a decrease in the distance I can walk in 6 min.

Since I am old and on heavy oxygen 24/7, I will gladly kill any government bureaucrat who tries to limit my bottle usage or mobility!

I will be seeing my doctor to be evaluated to get a portable oxygen concentrator, hoping I will get it. The company I use is limited as to what I can get.

I had to buy my own portable concentrator. I use it when I go out because with this device I have a better and easier life. We all should have access to a portable lightweight machine like I have bought.

The tanks do not last very long and they are too heavy.

With arthritis in hips, knees, and shoulders, I can carry or lift only a limited weight, less than the usual woman's purse. Without my portable oxygen concentrator, I would be unable to travel.

I hate it. I live in an apartment with steps, and the cylinder is too heavy for me, so I do not like going out anymore.

Please do not restrict our lives more by making us use these heavy tanks.

Given my high-flow oxygen needs and my desire and ability to exercise and to be mobile, I have found the liquid oxygen system to be the best at supporting me to live the fullest life possible in the face of serious, life-threatening health issues.
Cumbersome/heavy

Lack of mobility

Cumbersome/heavy

Freedom/autonomy

Cumbersome/heavy

Insufficient support for breathing

Insufficient support

for breathing

Independence

Cumbersome/heavy

Mobility

Freedom of choice

Freedom of choice

Insufficient support

Cumbersome/heavy

Cumbersome/heavy

Mobility

Cumbersome/heavy

Freedom/autonomy

Quality of life

Mobility

Quality of life

(continued) 
Table 3. Continued

\begin{tabular}{|c|c|}
\hline Excerpt of Participants' Comments & Initial Code \\
\hline I need supplemental oxygen beyond my at-home concentrator; without this freedom, I have no reason to continue. & Freedom/autonomy \\
\hline $\begin{array}{l}\text { To be housebound would be a death sentence for me. Small cylinders run out too soon, and large cylinders are beyond } \\
\text { my capability to transport. I need a portable concentrator to improve my quality of life and give me a reason to go on. }\end{array}$ & $\begin{array}{l}\text { Mobility } \\
\text { Quality of life } \\
\text { Hope }\end{array}$ \\
\hline $\begin{array}{l}\text { I've been Stage } 4 \text { for } 16 \text { y and care for myself. The liquid oxygen and heliox system have enabled me to have freedom } \\
\text { and better health because I can exercise and shop and have a social life. }\end{array}$ & $\begin{array}{l}\text { Freedom/autonomy } \\
\text { Quality of life }\end{array}$ \\
\hline $\begin{array}{l}\text { When I had the heavy cylinders, I was exhausted just getting to my car and in or out, so I became a hermit because it } \\
\text { was just too hard to function. }\end{array}$ & Cumbersome/heavy \\
\hline $\begin{array}{l}\text { The tanks make it very difficult to plan for an 8-h event because of the number of tanks it takes to sustain me, which } \\
\text { would be 4-6 large E tanks. Liquid oxygen is so much more portable. My quality of life has decreased. }\end{array}$ & $\begin{array}{l}\text { Insufficient support } \\
\text { for breathing } \\
\text { Quality of life }\end{array}$ \\
\hline $\begin{array}{l}\text { My tank is too heavy for me to go for a walk. Pulling the weight of the tank uses my oxygen and my sats fall quickly. I } \\
\text { also cannot grocery shop. }\end{array}$ & $\begin{array}{l}\text { Cumbersome/heavy } \\
\text { Quality of life }\end{array}$ \\
\hline $\begin{array}{l}\text { I don't like my forced upon me portable, they took away my liquid oxygen on which I did so much better. I hardly have } \\
\text { the strength to pull in the oxygen on the system I have now. }\end{array}$ & Freedom of choice \\
\hline $\begin{array}{l}\text { I would like something even smaller to carry outside of my house because I am such a small person. It is hard on my } \\
\text { body to carry anything because I'm so little. }\end{array}$ & Cumbersome/heavy \\
\hline The heavy tanks make it impossible for me to go anywhere alone. I can not handle them & $\begin{array}{l}\text { Cumbersome/heavy } \\
\text { Lack of mobility }\end{array}$ \\
\hline My portable unit doesn't last long enough for me to go too far. It will only last $1.8 \mathrm{~h}$. & $\begin{array}{l}\text { Insufficient support } \\
\text { for breathing }\end{array}$ \\
\hline I would love to have a portable oxygen but it is too expensive! & Cost-prohibitive \\
\hline I weigh $106 \mathrm{lbs}$ and an E cylinder is impossible for me to carry around. & Cumbersome/heavy \\
\hline
\end{tabular}

smaller devices allowed for greater autonomy. This is succinctly expressed in one respondent's comment: "Please do not restrict our lives more by making us use these heavy tanks." The importance of autonomy is underscored by another subject's comment that goes beyond the liberating benefits of access to oxygen: "I need supplemental oxygen beyond my at home concentrator; without this freedom I have no reason to continue."

The responses provided useful insights into the value subjects place on their autonomy as well as snapshots of their lives using portable LTOT devices. One subject stated, "I've been Stage 4 for $16 \mathrm{y}$ and care for myself. The liquid oxygen and heliox system have enabled me to have freedom and better health because I can exercise and shop and have a social life."

The data revealed that autonomy for subjects was a high priority. These comments from the subjects provide further examples of the emphasis on freedom, which they described as heavily dependent on access to a particular LTOT device.

- I would love to be able to go when and where I wanted, but it's such a bother to worry about having enough cylinders to get me through a trip or visit. I would love to have the option for a lightweight portable concentrator instead of the cylinders. $\mathrm{My}_{2}$ supplier says that since Medicare won't pay for them, I can't get one, they're too expensive.
- I use the small C containers when I am out and the concentrator when I am at home. These work very well for me, allowing me to do almost everything I want. A portable concentrator would be better, but I can't afford it. Medicare has already reduced the amount it will pay for, leaving me at risk of not having anything. If you change the available choices, I will be stuck at home, unable to do much of anything. Please take Medicare back to its full coverage for the best options available.

\section{Isolation Versus Integration}

Subjects also viewed the difference in device as contributing to how they participated in their communities. One comment exemplifies the importance subjects ascribe to integration: "To be housebound would be a death sentence for me." The use of tanks was described as limiting subjects' ability to engage in their religious, civic, and social spheres. The following comment encapsulates the subjects' experience with cylinders: "Using the cylinders restricts time I spend outside my immediate home/yard. While with a cylinder, I'm ready to be *done* . . . so much energy is wasted!"

LOX and POCs were described as the preferred devices to promote continued integration in subjects' personal and professional lives. This is illustrated by one subject who states, 'I'll be in San Francisco next week for a confer- 
ence, and will be renting a scooter to get me to meetings because I would have to carry four $\mathrm{C}$ tanks if I were to walk to all the places I will have to go in the time I have between meetings. It would be easier with LOX and the large Smartdose, but I would probably still have to return to the hotel to refill after about $8 \mathrm{~h}$. For a situation like the conference, there really isn't anything that will provide enough $\mathrm{O}_{2}$ for me to be gone for up to $16 \mathrm{~h}$ without going to a refill. For daily living, LOX is much preferable to having to carry several tanks. I'm lucky in that I don't require $\mathrm{O}_{2}$ unless I'm walking fast and carrying stuff (including the tanks!).

The data revealed that subjects who had limited or no access to LOX or POCs were more isolated as they were not able to engage in their preferred community and social activities. Subjects who enjoyed continued integration were heavily reliant on their LTOT device. However, it must also be noted that subjects who described their attempts to remain integrated also employed other coping strategies (eg, minimizing walking) to ensure that they can engage in their preferred activities.

\section{Quality of Life}

The level of comfort and ability to effectively conduct daily activities figured prominently in the subjects' responses. The type of devices available to them seemed to be inextricably linked with the quality of life described in the data. According to one respondent, "To be housebound would be a death sentence for me. I need a portable concentrator to improve my quality of life, to improve my life and give me a reason to go on."

The reality expressed by the subjects reflects the impact that the availability (or the lack) of the devices has on their quality of life. In explaining the situation, one respondent rates the quality of life without a concentrator: "The oxygen company I was with lost their bid with Medicare and though the portable concentrator works best for me, the company I am with now seems to be having problems getting Medicare's approval. When I used one I was actually able to get around more, even going places with my family. The doctor's office is the only place I can go now. My quality of life is ' 0 '."

The subjects' description of the impact that the LTOT devices they could access on their quality of life is a recurrent theme in the data analysis. This is worth exploring further in subsequent inquiries of this nature.

The results of the thematic analysis suggest that oxygen-dependent individuals with COPD may experience varying degrees of reduction in mobility due to LTOT devices. Additionally, other challenges relevant to the use of LTOT devices may restrict these individuals from participating in family and community activities, thereby adversely affecting their perceived quality of life.

\section{Discussion}

This study's findings suggest that LTOT devices play a major role in subjects' overall perceived quality of life as it relates to their ability to maintain an acceptable level of mobility and their perception regarding freedom of choice. The results also indicate that subjects perceive cumbersome portable LTOT devices as contributing significantly to inhibiting their daily activities, their choice of work, and their ability to interact fully with their social environment. They also expressed fear of the hazards associated with using oxygen cylinders.

Our findings are unique because the study focused on the perspectives of individuals who are living with COPD rather than presenting numeric data from statistical analysis. For example, some subjects reported that using an "E" oxygen cylinder as a portable LTOT device consumes too much of their energy because of having to pull the oxygen cylinder behind them. Additionally, they expressed frustration at having to carry one cylinder and store another if they need to be outside for $>9 \mathrm{~h}$ at an oxygen flow of $1 \mathrm{~L} / \mathrm{min}$. The subjects' linkage of portable oxygen cylinders to lack of mobility, as well as they linkage of liquid oxygen to longer time of operation and to the feeling of having sufficient support for breathing, is consistent with the findings of a longitudinal study showing that the use of liquid oxygen was linked with more walking and more breathing hours. ${ }^{15}$ This study used a questionnaire to elicit information from subjects about their health-related quality of life specifically, after initiation of LTOT or after switching from a POC to LOX. However, unlike our study, the researchers used quantitative data analysis techniques, which led them to conclude that LOX was significantly improving patients' overall quality of life mainly by increasing the number of outdoor activity hours and the ability to be able to walk longer distances. This might have a role in reducing exacerbation and improving overall muscle strength. Other studies have found that the use of a lightweight portable LTOT device is important in helping individuals comply with their prescribed oxygen therapy, increase their outside activities, increase exercise capacity, and improve health-related quality of life. ${ }^{16,17}$

To our knowledge most of the studies that focused on the quality of life for patients with COPD in general, taking into consideration the type of the oxygen devices used, have employed quantitative methodologies. Our study took a qualitative approach in analyzing robust, text-rich data describing subjects' experiences with LTOT devices to further support our previous quantitative study. We found that perceived mobility, feelings of fear, freedom of choice, and overall perceived quality of life are associated with the type of oxygen devices that the subjects use.

As much as this study showed that the oxygen device might affect COPD patient's mobility and quality of life, 
we should also consider that this could also be related to the severity of their disease more than the device itself, as most of the subjects self-reported that they have moderate or severe COPD (Table 1). In fact, several studies have found that the severity of disease, age, and depression, play a major role in mobility and quality of life. ${ }^{8,18}$

A qualitative study that was conducted in Australia recruited 17 subjects from the PELICAN (Primary Care Early Intervention for COPD Management) project to gain a deeper understanding of the impact of a new COPD diagnosis on the individuals' quality of life from their perspectives. ${ }^{19}$ Thematic analysis of in-depth interviews enabled the researchers to identify 5 main themes regarding the subjects' perspectives of the impact of a COPD diagnosis. Of the 5 main themes identified, 3 were reaction to diagnosis, impact of the diagnosis on function and behavior, and the factors that influence self-management. The researchers found that 12 subjects had limitations in activities of daily living due to dyspnea. They also found that the subjects' COPD self-management was suboptimal because of a lack of knowledge about COPD and its longterm consequences. This study suggests that health care providers may need to be more actively engaged in informing individuals with COPD about the possible impact of the disease, potential treatments, and an individualized management plan.

The findings of our study are relevant to clinical practice in many aspects. First, taking into consideration patients' perspectives about their disease and treatment is important to achieve patient-centered care. Numerical data based on statistical analyses will give the health care provider a quantitative picture about the disease's related impacts, but qualitative data about what truly matters to individuals living with COPD and the challenges they face in trying to cope with this disease will provide more indepth information that will amplify the quantitative findings, resulting in a more detailed picture of the disease's impact on individuals' quality of life.9,20,21 Obtaining an individual's perspective regarding her or his experience with a specific type of oxygen device and using that information to facilitate appropriate LTOT prescription may ultimately help to keep the patient physically active. Moreover, if the primary physician encourages the patient with COPD to exercise or at least walk some distance every day, the physician should consider the type of device that the patient uses. If an individual were prescribed a stationary LTOT device with or without a portable device, the health care provider should endeavor to ascertain whether the device will provide optimal support during exercise or ambulation, as this may ultimately affect the individual's quality of life.

Our study has some limitations attributable to surveybased research. Because the investigators did not meet with the subjects in person, there is no way of knowing who really answered the survey questions. Although the link to the survey was published on the COPD Foundation's website, the investigators have no knowledge of how the COPD Foundation determines if their members are in fact individuals with COPD. However, it is unlikely that individuals who do not have COPD would take the time to respond to 36 survey questions and then provide detailed and passionate comments about their experiences with LTOT devices in response to our invitation at the end of the survey to share additional comments or opinions. Another limitation of this study is that the study subjects were predominantly female, which is not consistent with the traditional demographic profile of the COPD population in the United States. However, over the past 2 decades, there has been a dramatic increase in women dying from COPD. ${ }^{20}$ Currently, women in the United States are more likely to have COPD $(6.6 \%)$ than men $(5.4 \%) .^{22}$

With regard to COPD severity, subjects were asked to indicate if they had mild, moderate, or severe COPD. This is not consistent with the Global Initiative for Chronic Obstructive Lung Disease (GOLD) classification of airflow limitation severity in COPD, which includes a "very severe" category; this is another limitation of our study. The study used a qualitative approach in which the researchers looked for patterns in subjects' responses and assigned specific words and phrases to categories. This process is vulnerable to researcher bias. To limit this effect on the results, we used a special feature of the NVivo software to auto code and compare the themes and patterns identified by the investigators to those generated by the software. Additionally, the research team engaged in an iterative analysis of the coded themes to facilitate consensus, and the subjects' responses were analyzed by at least 3 members of the research team in an effort to achieve inter-rater reliability.

The findings of this exploratory study indicate that quality of life for oxygen-dependent individuals with COPD is closely linked to their perceptions of the degree of mobility that their portable LTOT device affords them. Moreover, it is obvious from the themes that emerged (eg, freedom, autonomy, hope, isolation, and integration) that physiological outcomes such as $\mathrm{FEV}_{1}, \mathrm{P}_{\mathrm{aCO}}, \mathrm{P}_{\mathrm{O}_{2}}$, and $\mathrm{S}_{\mathrm{pO}_{2}}$, as well as functional capacity such as the 6-min walk distance, may not be adequate surrogate measures of quality of life for this population. A statement of COPD research priorities issued by the American Thoracic Society in conjunction with the European Respiratory Society has highlighted the need for studies designed to determine which outcomes matter most to patients with COPD. Our descriptive study provides valuable information for future studies that aim to bridge the knowledge gap identified by the American Thoracic Society and the European Respiratory Society. 


\section{Perspectives From COPD Subjects on LTOT}

\section{Conclusion}

Oxygen-dependent individuals with COPD may be at risk of adverse outcomes associated with decreased mobility that is fostered by unsatisfactory physical and technical characteristics of portable oxygen cylinders and POCs. However, by discussing the various features and potential limitations of a portable oxygen delivery device with the patient, health care providers may be able to provide guidance for the utilization of a LTOT device that maximizes the patient's mobility and does not inhibit his or her desire to participate in activities of daily living and engagement in the community.

\section{ACKNOWLEDGMENTS}

The authors would like to thank Mr Bill Clark for facilitating posting of the survey on the COPD360social social media site, and all the individuals living with COPD who took the time to share their experiences with LTOT devices.

\section{REFERENCES}

1. Stoller JK, Panos RJ, Krachman S, Doherty DE, Make B, et al. Oxygen therapy for patients with COPD: current evidence and the long-term oxygen treatment trial. Chest 2010;138(1):179-187.

2. Tanni SE, Vale SA, Lopes PS, Guiotoko MM, Godoy I, Godoy I. Influence of the oxygen delivery system on the quality of life of patients with chronic hypoxemia. J Bras Pneumol 2007;33(2):161.

3. Casaburi R, Porszasz J, Hecht A, Tiep B, Albert RK, Anthonisen $\mathrm{NR}$, et al. Influence of lightweight ambulatory oxygen on oxygen use and activity patterns of COPD patients receiving long-term oxygen therapy. COPD 2012;9:3-11.

4. Gill DL, Hammond CC, Reifsteck EJ, Jehu CM, Williams RA, Adams MM, et al. Physical activity and quality of life. J Prev Med Public Health 2013;46(Suppl 1):S28-S34.

5. Mendoza L, Horta P, Espinoza J, Aguilera M, Balmaceda N, Castro A, et al. Pedometers to enhance physical activity in COPD: a randomised controlled trial. Eur Respir J 2015;45(2):347-354.

6. Puhan MA, Gimeno-Santos E, Cates CJ, Troosters T. Pulmonary rehabilitation following exacerbations of chronic obstructive pulmonary disease. Cochrane Database Syst Rev 2016;12:CD005305.

7. Wootton SL, Ng LW, McKeough ZJ, Jenkins S, Hill K, Eastwood $\mathrm{PR}$, et al. Ground-based walking training improves quality of life and exercise capacity in COPD. Eur Respir J 2014;44(4):885-894.

8. Hartman JE, Boezen HM, de Greef MH, Ten Hacken NH. Physical and psychosocial factors associated with physical activity in patients with chronic obstructive pulmonary disease. Arch Phys Med Rehabil 2013;94(12):2396-402.
9. Miravitlles M, Cantoni J, Naberan K. Factors associated with a low level of physical activity in patients with chronic obstructive pulmonary disease. Lung 2014;192(2):259-265.

10. Arnold E, Bruton A, Donovan-Hall M, Fenwick A, Dibb B, Walker E. Ambulatory oxygen: why do COPD patients not use their portable systems as prescribed? A qualitative study. BMC Pulm Med 2011; 11:9.

11. Tsara V, Serasli E, Katsarou Z, Tsorova A, Christaki P. Quality of life and social-economic characteristics of greek male patients on long-term oxygen therapy. Respir Care 2008;53(8):1048-1053.

12. Mussa C, Tonyan L, Chen Y, Vines D. Perceived satisfaction with long-term oxygen delivery devices affects perceived mobility and quality of life of oxygen-dependent individuals with COPD. Respir Care 2018;63(1):11-19.

13. Patton MQ. Qualitative evaluation and research methods. Newberry Park, California: Sage Publications; 1990.

14. Zamawe FC. The implication of using NVivo software in qualitative data analysis: evidence-based reflections. Malawi Med J 2015;27(1): 13-15.

15. Czajkowska-Malinowska M, Poltyn B, Ciesielska A, Kruza K, Jesionka P. Comparison of the results of long term oxygen therapy in patients treated sequentially using stationary or a portable source of oxygen. Pneumonol Alergol Pol 2012;80(4):308-316.

16. Nasilowski J, Przybylowski T, Zielinski J, Chazan R. Comparing supplementary oxygen benefits from a portable oxygen concentrator and a liquid oxygen portable device during a walk test in COPD patients on long-term oxygen therapy. Respir Med 2008;102(7):10211025.

17. Gustafson T, Lofdahl K, Strom K. A model of quality assessment in patients on long-term oxygen therapy. Respir Med 2009;103(2):209215.

18. Balbo NA, Acosta MA, Kevorkof GV. Quality of life in patients with COPD and long term oxygen therapy. Rev Fac Cien Med Univ Nac Cordoba 2012;69(2):83-89.

19. Ansari S, Hosseinzadeh H, Dennis S, Zwar N. Patients' perspectives on the impact of a new COPD diagnosis in the face of multimorbidity: a qualitative study. NPJ Prim Care Respir Med 2014;24: 14036.

20. Lewin S, Glenton C, Munthe-Kaas H, Carlsen B, Colvin CJ, Gulmezoglu $\mathrm{M}$, et al. Using qualitative evidence in decision making for health and social interventions: an approach to assess confidence in findings from qualitative evidence syntheses (GRADE-CERQual). PLoS Med 2015;12(10):e1001895.

21. Disparities in Lung Health Series. Taking her breath away: the rise of COPD in women. New York: American Lung Association; 2013.

22. Wheaton AG, Cunningham TJ, Ford ES, Croft JB; on behalf of the US Department of Health and Human Services: Centers for Disease Control and Prevention. Employment and activity limitations among adults with chronic obstructive pulmonary disease: United States, 2013. MMWR Morb Mortal Wkly Rep 2015;64(11):289-295.

This article is approved for Continuing Respiratory Care Education credit. For information and to obtain your CRCE

(free to AARC members) visit www.rcjournal.com

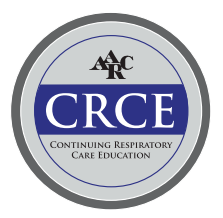

